\title{
MODELLING OF THE DRAWING PROCESS PARAMETERS USING EXPERIMENTAL DATA - THE CASE A PIECE OF STEEL
}

\section{Aurelia CHIOIBAS ${ }^{1}$}

${ }^{1}$ Lecturer eng, Ph. D., Dep. IMAN, Naval Academy "Mircea cel Batran", chioibasaura@yahoo.com

\begin{abstract}
This modeling is accomplished through surfaces responses method. The proposed method considers the links between process parameters and corresponding responses as surfaces in the dimensional space of variables. In this method the independent variables are varied simultaneously, taking a limited number of values considered in the experiment, called levels. This enables the highlighting interactions between independent variables, which contributes to more accurately determine the global optimum. Although the independent variables are varied simultaneously, their main effects and higher order and their interactions can be determined separately so that it can establish order and exclude those variables influence without significant influence.
\end{abstract}

Key words: the drawing force, method of response surface

\section{Introduction}

Experimental the research purposes were as follows:

- verifying the results of numerical simulation finite element or correcting them;

- $\quad$ statistical modeling of the relationship between some characteristics, such as drawing force, and drawing parameters, such as the drawing coefficient " $\mathrm{m}$ " and the thinning coefficient " $m_{y}$ ". To achieve these purposes was used statistical programming experiences that led to obtain experimental programs. After carrying out experiments using an experimental stand was obtained experimental data table, necessary to determine the response surface of characteristic studied. It has been established models proposed for the drawing force, and the coefficients of this model were determined by the method of smallest squares, and then the response surface were analyzed, according to the models determined. The modeling of experimental data using a proven to be expensive due to the time needed to perform of the experiments, equipment and materials used.

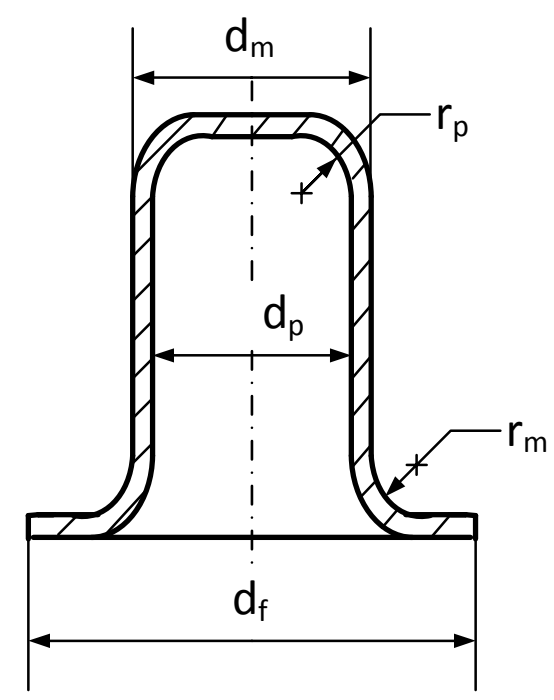

Fig. 1. Nit tubular 
"Mircea cel Batran" Naval Academy Scientific Bulletin, Volume XIX - 2016 - Issue 2

The journal is indexed in: PROQUEST / DOAJ / Crossref / EBSCOhost / INDEX COPERNICUS / DRJI / OAJI I JOURNAL INDEX / I2OR / SCIENCE LIBRARY INDEX / Google Scholar / Academic Keys/ ROAD Open Access I

Academic Resources / Scientific Indexing Services / SCIPIO I JIFACTOR

\section{Design of the experimental programs}

On the basis of experimental research on drawing successive strip thinning state landmark "tubular rivet" [1], which is a part of the button quickly realized F.A.M. Galati (Figure 1).

Main factors cupping small parts, which were considered in the drawing experimental programs are drawing coefficient with and without thinning, punch diameter or the die, punch and die radius.
Changing them is within the values recommended in the literature [2]. They were to the compilation of experimental programs required to obtain mathematical models of the 2nd order interactions of some important features of drawing [3].

After carrying out the technology calculations for drawing with thinning tape [4], in order to obtain the item mentioned, resulted Table 1 [5].

Tab. 1. Experimental conditions and results obtained from the deformation of annealed steel strip

\begin{tabular}{|c|c|c|c|c|c|c|c|c|c|c|}
\hline \multirow{2}{*}{$\begin{array}{l}\text { Nr. } \\
\text { exp. }\end{array}$} & \multicolumn{2}{|c|}{ Punch } & \multicolumn{2}{|c|}{ Die } & \multirow{2}{*}{$\begin{array}{c}\mathrm{j} / 2 \\
{[\mathrm{~mm}]}\end{array}$} & \multirow{2}{*}{$\begin{array}{c}D_{\text {nick }} \\
{[\mathrm{mm}]}\end{array}$} & \multirow{2}{*}{$\begin{array}{r}F_{\text {a meas }} \\
{[\mathrm{daN}]}\end{array}$} & \multirow[t]{2}{*}{$\mathrm{m}$} & \multirow[t]{2}{*}{$m_{y}$} & \multirow[t]{2}{*}{$\mathrm{m}_{\mathrm{glt}}$} \\
\hline & Nr. & $\mathrm{d}_{\mathrm{p}}[\mathrm{mm}]$ & Nr. & $\mathrm{d}_{\mathrm{m}}[\mathrm{mm}]$ & & & & & & \\
\hline 1. & 1. & 5,52 & 1. & 6 & 0,24 & 11 & 168,89 & 0,56 & 1 & 0,56 \\
\hline 2. & 2. & 8,02 & 2. & 8,5 & 0,24 & 17 & 245,84 & 0,57 & 1 & 0,57 \\
\hline 3. & 3. & 10,52 & 3. & 11 & 0,24 & 17 & 296,47 & 0,65 & 1 & 0,65 \\
\hline 4. & 4. & 5,36 & 1. & 6 & 0,32 & 11 & 178,72 & 0,55 & 1 & 0,55 \\
\hline 5. & 5. & 7,86 & 2. & 8,5 & 0,32 & 17 & 245,84 & 0,58 & 0,8 & 0,46 \\
\hline 6. & 6. & 10,36 & 3. & 11 & 0,32 & 17 & 245,84 & 0,65 & 1 & 0,65 \\
\hline 7. & 7. & 5,2 & 1. & 6 & 0,4 & 11 & 168,89 & 0,56 & 1 & 0,56 \\
\hline 8. & 8. & 7,7 & 2. & 8,5 & 0,4 & 17 & 236,43 & 0,58 & 1 & 0,58 \\
\hline 9. & 9. & 10,2 & 3. & 11 & 0,4 & 17 & 217,44 & 0,65 & 1 & 0,65 \\
\hline
\end{tabular}

The significance of notations:

$\mathrm{m}=$ the drawing coefficient admissible;

$\mathrm{m}_{\mathrm{y}}=$ the thinning coefficient admissible;

$\mathrm{m}_{\mathrm{glt}}=$ the global total admissible coefficient;

$\mathrm{d}_{\mathrm{p}}=$ the punch diameter;

$\mathrm{d}_{\mathrm{m}}=$ the die diameter;

$\mathrm{j}=$ the clearance between the active elements;

\section{The method of response surface}

This method considers the connections between process parameters and their appropriate responses, such as some surfaces in the dimensional space of variables. In this method the independent variables are varied simultaneously, taking a limited number of values, considered in the area of experimentation, called levels.This allows the highlighting the interactions between the independent variables, which contributes to more accurate determine the global optimum.Although the independent variables are varied simultaneously, both main effects and higher order and their interactions can be determined separately. This makes it possible to establish the order of variables influence and excludes those without significant influence. It can verify the accuracy of the mathematical model and refine this model.
$D_{\text {nick }}=$ the diameter of the band is slited to allow the pulling it in the form of the part wall and to prevent breakage of the base-wall rounding radius, respectively flange-wall;

$\mathrm{F}_{\text {a meas }}=$ the drawing measured force;

$r_{\mathrm{p}}=2 \mathrm{~mm}$, is the punch radius;

$r_{m}=2 \mathrm{~mm}$, is the die radius.

Using the method of response surface to determining mathematical models of deformation process involve the following steps:

1. choice of characteristic responses that are studied;

2. consider choice of parameters, which influence the responses considered;

3. determining areas of variation corresponding to each parameter considered;

4. choice of form and complexity of the mathematical model;

5. choosing the type of experimental program; 
"Mircea cel Batran" Naval Academy Scientific Bulletin, Volume XIX - 2016 - Issue 2

The journal is indexed in: PROQUEST / DOAJ / Crossref / EBSCOhost / INDEX COPERNICUS / DRJI / OAJI / JOURNAL INDEX / I2OR / SCIENCE LIBRARY INDEX / Google Scholar / Academic Keys/ ROAD Open Access I Academic Resources / Scientific Indexing Services / SCIPIO / JIFACTOR

6. determining levels of variation of each parameter and coding of these levels;

7. realization of experimental program;

8. creating experimental conditions: equipment and appliances, installations;

9. experiments execution and measurement of responses;

10. determining the mathematical model coefficients;

\section{The choice of form and complexity models}

In the most general case, the relationship between the parameters and characteristics of a process can be in the form of a polynomial approximation, which in the parameter space is represented by a response surface. The response surface shape complexity is reflected in the complexity of the mathematical model. The choice of model complexity is envisaged that by choosing a model with maximum complexity, the statistical analysis highlights terms insignificant, they can be eliminated and obtain a simplification of the
11. verifying the adequacy of the model determined;

12. verifying the significance of coefficients;

12. establishing confidence intervals and error for predicting the response measured:

13. transformation coefficients for the model with natural variables.
model.Given these considerations were proposed models of second order with interaction for both the connection between the force drawing and the two parameters, the coefficient of drawing and coefficient of thinning as well as the link between the drawing force and the globally coefficient total drawing.General expressions of these patterns are given by the relations (1) and (2) [3].This model of equation (1) can be represented as a curve as shown in Figure 1, and the one given by relation (2) is a surface similar to that of Figure 2.

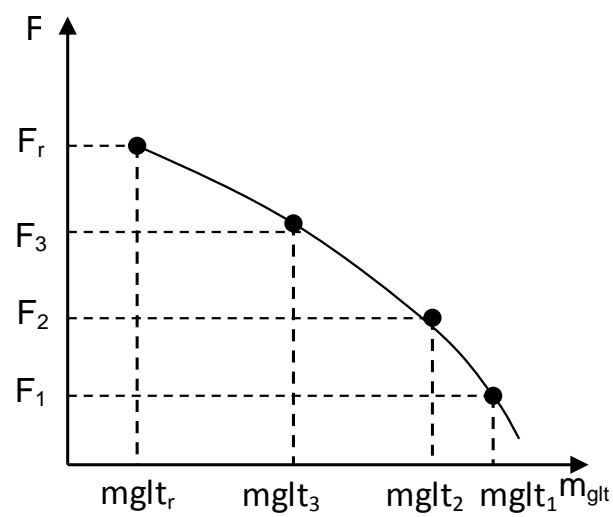

Figura 1. Alura funcţiei $F=f(m g l t)$

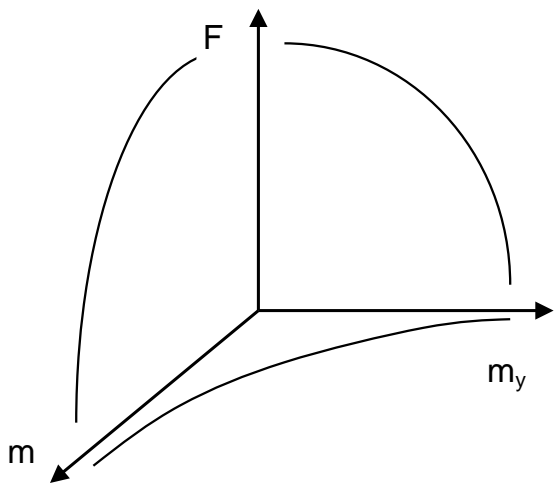

Figura 2. Alura funcţiei $F=f(m, m y)$

$$
\begin{aligned}
& F=a_{0}+a_{11} \cdot m_{\text {glt }}+a_{22} \cdot m_{\text {glt }}^{2} . \\
& F=b_{0}+b_{1} \cdot m+b_{2} \cdot m_{y}+b_{11} \cdot m^{2}+b_{22} \cdot m_{y}^{2}+b_{12} \cdot m \cdot m_{y} .
\end{aligned}
$$

Determining the models coefficients through the smallest squares method

This method provides a minimal dispersion of the coefficients determined.The smallest squares method proposed by Gauss which allows adjustment of regression function of experimental data is based on minimizing the sum of the squares of the differences between the measured variables of response $y$ in the experimental points and $\tilde{y}$ values calculated using polynomial approximation determined. 
"Mircea cel Batran" Naval Academy Scientific Bulletin, Volume XIX - 2016 - Issue 2 The journal is indexed in: PROQUEST / DOAJ / Crossref / EBSCOhost / INDEX COPERNICUS / DRJI / OAJI / JOURNAL INDEX / I2OR / SCIENCE LIBRARY INDEX / Google Scholar / Academic Keys/ ROAD Open Access I Academic Resources / Scientific Indexing Services / SCIPIO / JIFACTOR

To correct application of the method of smallest squares, it is considered that following assumptions are met:

- corresponding to each data point, the errors made in determining parameter values $x_{u}$ are negligible compared to those of measured responses y;

- the measured responses $\mathrm{y}$ in $\mathrm{n}$ data points are independent sizes affected by random errors with approximately normal distribution;

- dispersions responses measured in all the $\mathrm{n}$ experimental points are equal to each other. When this condition is not satisfied, searching for a functional dependency, which ensures homogeneity of dispersion, by transforming measured responses

Because the $y$ responses measured in each experimental point are subject to errors $\varepsilon$, for each experimental point $u$ can write the difference $y-\tilde{y}$, order to obtain the deviation from regression or the residual:

$$
\mathrm{y}_{\mathrm{u}}=\varepsilon_{\mathrm{u}}
$$

$y_{u}$ replacing with the expression model approximation, rising to square both members and applying $\sum_{u=1}^{n}$ for all the experimental points there is obtained the sum $S$ that must be minimized in relation to $b_{i}$ coefficients, i.e.:

$$
\mathrm{S}=\sum_{\mathrm{u}=1}^{\mathrm{n}} \varepsilon_{\mathrm{u}}^{2}=\min
$$

The minimum value of $\mathrm{S}$ is given by the system of linear equations solutions obtained by annulling the partial derivatives of that sum in relation to all $k+1$ coefficients. By calculating the $k+1$ partial derivatives of $S$ in relation to each of the $k+1$ coefficients of the polynomial approximation, from the expression of the model of approximation to obtain a system of $n+1$ linear equations with respect to the coefficients bi, called the system of normal equations and from whose solution resulting coefficient values $b_{i}$ of the model approximation.

When solving the system of normal equations, by applying the matrix inversion method is obtained the following matrix equation necessary for calculating of the coefficients $b_{i}$ of the model approximation:

$$
B=\left(X^{\top \cdot} X\right)^{-1} \cdot X^{\top} \cdot Y
$$

in that: B - the column vector of the coefficients of the approximation model; $Y$ - column vector of responses $y$ measured at each point of the experimental program; $X$ - matrix of independent variables; $X^{\top}$ - transposed matrix of independent variables; $X^{\top} \cdot X$ - square matrix; $\left(X^{\top} \cdot X\right)^{-1}$ inverse square matrix; $X^{\top} \cdot Y$ - vector column.

The matrix of the independent variables $X$ has a number of columns equal to the number of terms of the polynomial approximation and a number of lines equal to the number of experiences. The first column has all the elements corresponding free terms equal to +1 . The corresponding columns of the first order terms coefficients have corresponding elements $\mathrm{m}$ and $\mathrm{m}_{\mathrm{y}}$ variables. Quadratic terms coefficients corresponding columns have elements corresponding columns $\mathrm{m}^{2}$ and $\mathrm{m}_{\mathrm{y}}{ }^{2}$ variables. The corresponding columns of the interactions terms coefficients between independent variables have the elements obtained from products columns elements of independent variables which determine that interaction, i.e. $m \cdot m_{y}$. Column vector of responses measured at each point of the experimental program contains experimentally determined value drawing force.

To building the model given by (1) the $X$ and $Y$ matrices are made up of the data of Table 1 and determine coefficients matrix. 
"Mircea cel Batran" Naval Academy Scientific Bulletin, Volume XIX - 2016 - Issue 2 The journal is indexed in: PROQUEST / DOAJ / Crossref / EBSCOhost / INDEX COPERNICUS / DRJI / OAJI I JOURNAL INDEX / I2OR / SCIENCE LIBRARY INDEX / Google Scholar / Academic Keys/ ROAD Open Access I Academic Resources / Scientific Indexing Services / SCIPIO / JIFACTOR

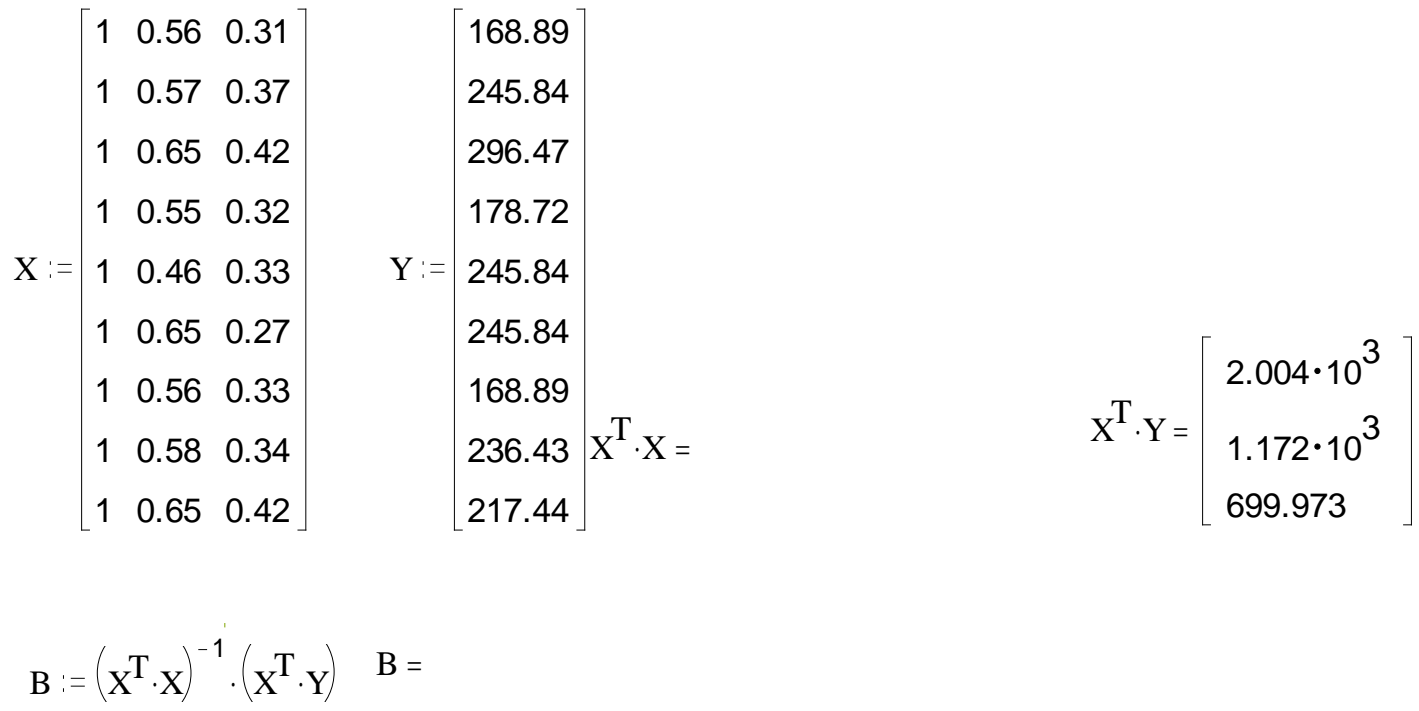

The drawing force determined according to the equation (1) band of $A 3 K$ is [5]:

$$
\mathrm{F}=35.57+136.31 \cdot \mathrm{m}_{\mathrm{glt}}+312.3 \cdot \mathrm{m}_{\mathrm{glt}}^{2}
$$

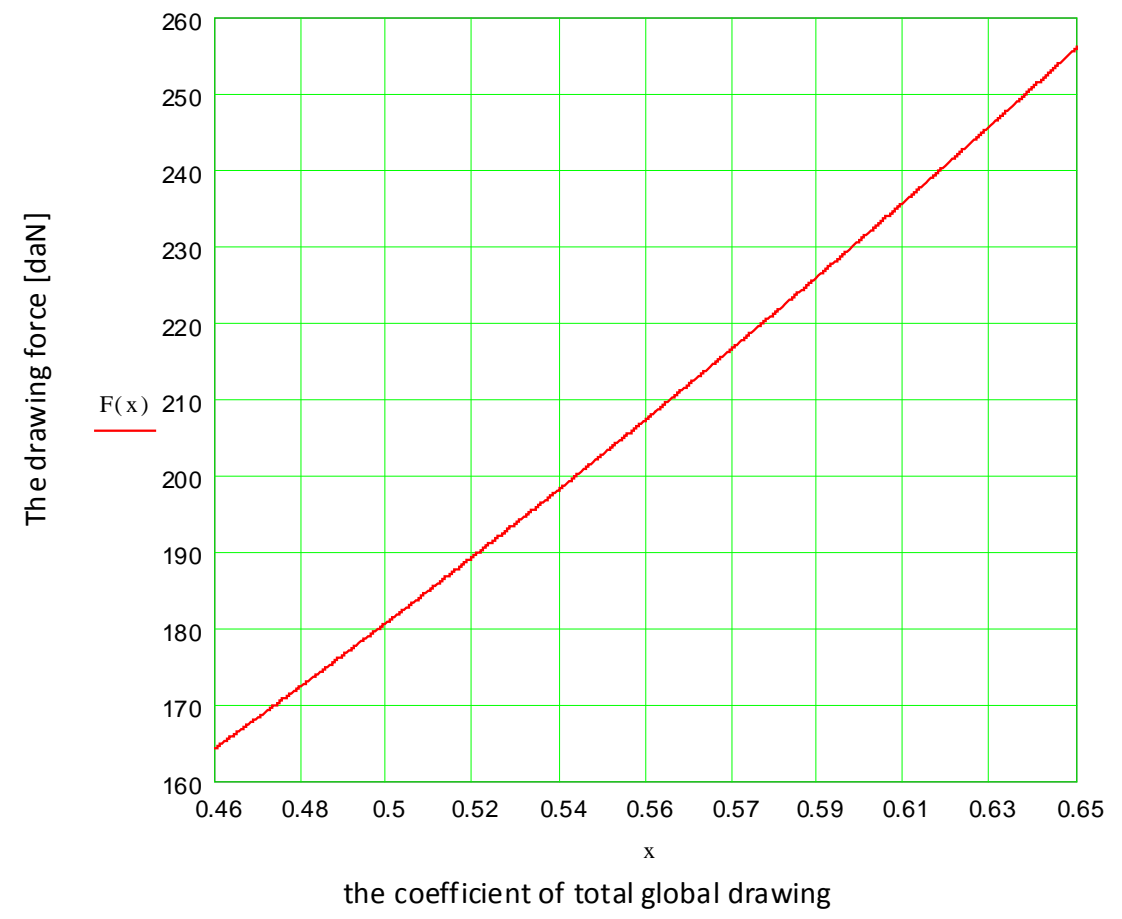

Figure 3.The variation drawing force depending the drawing global total, according to the model determined for annealed steel tape

Graphical representation of the proposed model for annealed steel is shown in Figure 3. 
"Mircea cel Batran" Naval Academy Scientific Bulletin, Volume XIX - 2016 - Issue 2

The journal is indexed in: PROQUEST / DOAJ / Crossref / EBSCOhost / INDEX COPERNICUS / DRJI / OAJI / JOURNAL INDEX / I2OR / SCIENCE LIBRARY INDEX / Google Scholar / Academic Keys/ ROAD Open Access I Academic Resources / Scientific Indexing Services / SCIPIO / JIFACTOR

$X:=\left[\begin{array}{cccccc}1 & 0.56 & 1 & 0.31 & 1 & 0.56 \\ 1 & 0.57 & 1 & 0.32 & 1 & 0.57 \\ 1 & 0.65 & 1 & 0.42 & 1 & 0.65 \\ 1 & 0.55 & 1 & 0.30 & 1 & 0.55 \\ 1 & 058 & 0.8 & 033 & 0.64 & 0.46 \\ 1 & 065 & 1 & 042 & 1 & 0.65 \\ 1 & 056 & 1 & 0.32 & 1 & 0.56 \\ 1 & 058 & 1 & 0.34 & 1 & 0.58 \\ 1 & 0.65 & 1 & 0.42 & 1 & 0.65\end{array}\right] Y:=\left[\begin{array}{c}168.9 \\ 245.8 \\ 296.5 \\ 178.7 \\ 245.8 \\ 245.8 \\ 168.9 \\ 236.4 \\ 217.4\end{array}\right] \mathrm{B}:=\left(\mathrm{X}^{\mathrm{T}} \cdot \mathrm{X}\right)^{-1} \cdot\left(\mathrm{X}^{\mathrm{T}} \cdot \mathrm{Y}\right) \quad B:=\left[\begin{array}{c}432.489 \\ -0.565 \\ -853.512 \\ -0.454 \\ 119.484 \\ 767.104\end{array}\right]$

The drawing force determined according to the relationship (2) is annealed steel band[5]:

$$
F=432,489-0.565 \cdot m-853,512 \cdot m_{y}-0.454 \cdot m^{2}+119,484 \cdot m_{y}{ }^{2}+767,104 \cdot m \cdot m_{y}
$$

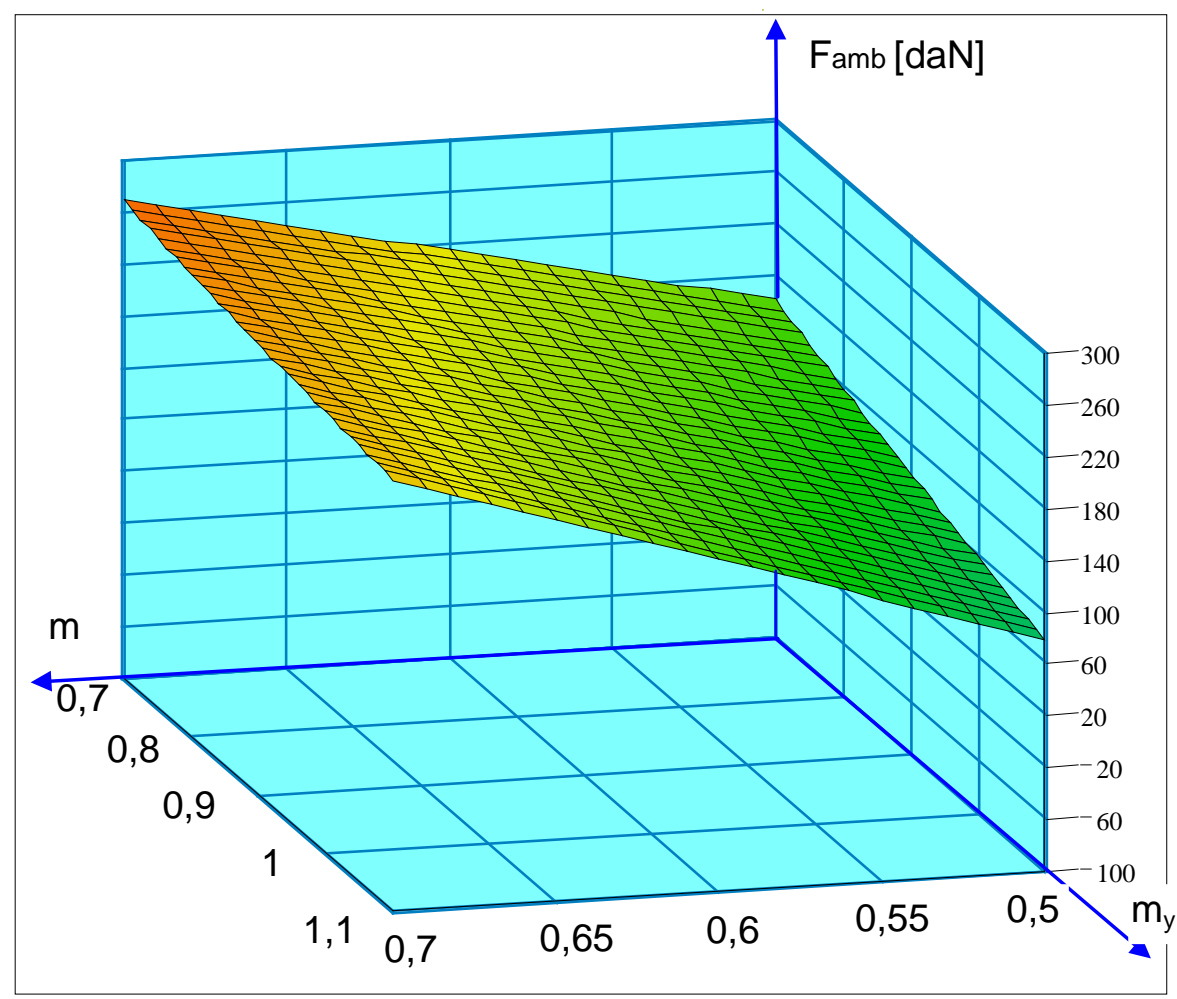

$\mathrm{N}$

Figure 4. Variation force drawing depending drawing coefficient and coefficient thinning, according to the model determined for annealed steel tape

Graphical representation of the proposed model for annealed steel is shown in Figure 4.

Analysis of curves and response surfaces corresponding patterns determined
To determine the accuracy of adjusting the model to experimental data is determined the error 
"Mircea cel Batran" Naval Academy Scientific Bulletin, Volume XIX - 2016 - Issue 2

The journal is indexed in: PROQUEST / DOAJ / Crossref / EBSCOhost / INDEX COPERNICUS / DRJI / OAJI I JOURNAL INDEX / I2OR / SCIENCE LIBRARY INDEX / Google Scholar / Academic Keys/ ROAD Open Access I

Academic Resources / Scientific Indexing Services / SCIPIO I JIFACTOR

prediction of measured response by the relationship:

$$
\varepsilon=\frac{F_{\text {measured }}-F_{\text {numerical modeling }}}{F_{\text {numerical modeling }}} \cdot 100[\%]
$$

where: $F_{\text {measured }}$ - experimentally determined value of the force; $F_{\text {numerical modeling - force value }}$ determined by the proposed model.
The relationship applies to every experience of the experimental program. For the annealed steel strip, the prediction error values determined are shown in Table 2.

They refer to the drawing force modeling depending drawing coefficient global total. It is noted that the maximum value of this error is $48 \%$, while the minimum is $7,6 \%$

Tabelul2.The values prediction errors corresponding

to the model $\mathrm{F}=\mathrm{a}_{0}+\mathrm{a}_{11} \cdot \mathrm{m}_{\mathrm{glt}}+\mathrm{a}_{22} \cdot \mathrm{m}^{2}{ }_{\text {glt }}$

\begin{tabular}{|c|c|c|c|}
\hline $\begin{array}{c}\text { Nr. } \\
\text { exp. }\end{array}$ & $F_{\text {meas }}[\mathrm{daN}]$ & $F_{\text {model }}[\mathrm{daN}]$ & Prediction error [\%] \\
\hline 1. & 168.89 & 209.8 & -19.5 \\
\hline 2. & 245.84 & 214.6 & 14.6 \\
\hline 3. & 296.47 & 256.1 & 15.8 \\
\hline 4. & 178.72 & 204.3 & -12.5 \\
\hline 5. & 245.84 & 165.3 & 48.7 \\
\hline 6. & 245.84 & 256.1 & -4.0 \\
\hline 7. & 168.89 & 211.5 & -20.1 \\
\hline 8. & 236.43 & 219.8 & 7.6 \\
\hline 9. & 217.44 & 254.5 & -14.6 \\
\hline
\end{tabular}

By analyzing the response surface obtained corresponding to the modeling drawing force depending on the drawing coefficient and the coefficient of thinning for the A3K strip it is noted that the largest slope presents the drawing coefficient $\left(25,5^{\circ}\right)$ compared to the coefficient thinning $\left(-5^{\circ}\right)$. It follows that the drawing force is influenced more by drawing coefficient values. Response surface is approximately flat, it can be concluded that the model drawing force is approximately linear in relation to the two parameters considered.This is understandable, because the variation of the two parameters is very small compared to the force variation.

Table 3 shows the values of the prediction error when response surface. It is noted that the maximum value is $80 \%$ and the minimum is $10,7 \%$.

Tab.3.The values prediction errors corresponding

to the model $F=b_{0}+b_{1} \cdot m+b_{2} \cdot m_{y}+b_{11} \cdot m^{2}+b_{22} \cdot m_{y}^{2}+b_{12} \cdot m \cdot m_{y}$.

\begin{tabular}{|l|r|r|r|r|r|r|r|r|r|}
\hline A3K & \multicolumn{1}{|c|}{ Exp1 } & \multicolumn{1}{|c|}{ Exp2 } & \multicolumn{1}{|c|}{ Exp3 } & \multicolumn{1}{|c|}{ Exp4 } & \multicolumn{1}{|c|}{ Exp5 } & \multicolumn{1}{|c|}{ Exp6 } & \multicolumn{1}{|c|}{ Exp7 } & \multicolumn{1}{|c|}{ Exp8 } & \multicolumn{1}{|c|}{ Exp9 } \\
\hline $\mathrm{F}_{\text {meas }}$ [daN] & 168.9 & 245.8 & 298.5 & 178.7 & 245.8 & 245.8 & 168.9 & 236.4 & 217.4 \\
\hline$F_{\text {model }}$ [daN] & 127.4 & 135.1 & 196.4 & 119.8 & 181.5 & 196.4 & 127.4 & 142.8 & 196.4 \\
\hline Prediction error [\%] & 32.5 & 82.0 & 52.0 & 49.2 & 35.4 & 25.2 & 32.5 & 65.6 & 10.7 \\
\hline
\end{tabular}


"Mircea cel Batran" Naval Academy Scientific Bulletin, Volume XIX - 2016 - Issue 2 The journal is indexed in: PROQUEST / DOAJ / Crossref / EBSCOhost / INDEX COPERNICUS / DRJI / OAJI / JOURNAL INDEX / I2OR / SCIENCE LIBRARY INDEX / Google Scholar / Academic Keys/ ROAD Open Access I Academic Resources / Scientific Indexing Services I SCIPIO I JIFACTOR

\section{CONCLUSIONS}

Data interpretation given by tab.1 led to the following conclusions:

$0 \quad$ in the same clearance of drawing with thinning be noticed an increase of processing force with increasing dimensions of active element because it increases the volume of the material deformed;in the case of the drawing is without thinning for any of the materials shown that the highest value of force corresponding to $8.5 \mathrm{~mm}$ diameter die, because to this experience is obtained walled cylindrical parts, so touching the most difficult conditions deformation;

o for the same diameter of the die, there was a slight decrease of drawing force with increasing of clearance because deformation conditions are improving.

Force values determined by calculation using literature relations are closer to the exprimentale differences appeared higher than those obtained by simulation. The differences are due to deformations technological system consisting press, die and piece, wear press, errors of settlement of the die on press, of the strip in stamping-die and die, variations in the thickness of the blank, the approximation in simulation coficientului friction existing practice.

Modeling was performed for the drawing force depending the drawing coefficient, the coefficient of thinning or the total global coefficient drawing. Proposed models were properly accounted for curves and response surfaces and were determined prediction errors. The maximum values of $48 \%$ and the minimum of $7 \%$ in the case of $F=F(m g l t)$ give the precision of the adjustment of the model to the experimental data.For model $F=$ $\mathrm{F}(\mathrm{m}, \mathrm{my})$. The maximum error of prediction was $80 \%$ and the minimum $10 \%$; mentioning is that six of the nine values are below $50 \%$. The slope of the highest recorded by drawing coefficient compared to the coefficient of thinning, indicates that first one is the highest influence on drawing force. Response surface is approximately flat, it can be concluded that the model drawing force is approximately linear in relation to the two parameters considered. This is understandable because the variation of the two parameters is very small compared to the force variation.

\section{BIBLIOGRAPHY}

$[1]{ }^{* * \star}$ Standard de firmă, S.F.558-96

[2] Romanovski, V.P., Ş̧tanţarea şi matriţarea la rece, (traducere din limba rusă), Editura Tehnică, 1970

[3] Ciocârdia, C., Drăgănescu, F., Tehnologia presării la rece , Îndrumar de laborator, U.P.B.

$[4]{ }^{* \star *}$ Ofertă generală, Galfinband S.A.

[5] Chioibas, A., Cercetări privind influenta condițiilor de deformare asupra calității pieselor ambutisate, Teza de doctorat, UPB, 2004 